\title{
TRACE IMPURITIES IN FUEIS BY ISOTOPE DILUTION MASS SPECTROMETRY
}

J. A. Carter, R. L. Walker and J. R. Sites

Oak Ridge National Laboratory*

Post Office Box $Y$

Oak Ridge, Tennessee 37830

INTRODUCTION

NOTICE

This report wes prepared as an account of work sponsored by the United States Government. Neither the United States nor the United States Atomic Energy Commission, nor any of their employees, nor any of their contractors, subcontractors, or their employees, makes any warranty, express or implied, or assumes any leatal liability or responsibility for the accuracy, completeness or usefulness of any information, apparatus; product or process disclosed, or represents that its use would not infringe privately owned rights,

Elements considered toxic to living organisms are present from the low ppb to the high ppm concentration range in coal and other fuels used as energy sources. With over half of the consumption of coal being used by large central power stations, the concentrated quantities of such potentially harmful elements as $\mathrm{Hg}, \mathrm{Cd}$, Ph, $U$ and others are appreciable. In the USA, for example, with an average annual coal consumption of over 500 million tons, any element present in coal at the 1 ppm level generates a waste problem of 500 tons. Many of the elements of interest are concentrated in the particulate fly ash or in the bottom slag. The use of efficient electrostatic precipitators, however, prevent most of the fly ash from being dispersed into the atmosphere. The fly ash and the bottom slag then become a storage and containment problem.

The major thrust of this research effort has been to demonstrate the capabilities of spark source and thermal emission mass spectrometry for determining the fate of trace elements in coal fired central power plants. Additionally, isotope dilution methods for the analyses of $\mathrm{Pb}, \mathrm{Cd}$ and $\mathrm{Hg}$ in gasolines and other petroleum fuels have been developed and used for referee and evaluation purposes.

\section{EXPERIMENTAI}

\section{Spark Source Mass spectrometry}

The sparte source mass spectrometer (SSMS) in this research was a commercial Mattauch-Herzog double focusing instrument; a schematic representation is shown in Fig. 1. In a SSMS analysis, an ion beam of the substance being investigated is produced in a vacuum by igniting a spark between two conductors employing a pulsed high-frequency potential of $50 \mathrm{kv}$. During this process, the electrode substance is evaporated and ionized. The produced ions are accelerated through the source slits by a constant potential of $25 \mathrm{kV}$ into an electrostatic radial field which functions as an energy filter. As the ions pass through the magnetic field, deflection occurs so that a splitting of the ion loeam takes place according to the mass-to-charge ratio; these charged particles impinge in focus on an ion-detector (photographic plate or photo multiplier) to form the mass spectrum. From the position of the lines and the relative intensity, elemental identification and abundance measurements can be made when the total ion beam current is known; this total ion current is measured by a monitor located just ahead of the magnetic analyzer. The resolution of the $A E I-702 R$ instrument used was greater than 3000. Ilford $Q-2$ photographic emulsions were used to record the mass spectra.

*operated for the U. S. Atomic Energy Commission under contract with the Union Carbide Corporation. 
- Conducting electrodes for general scan analyses were prepared by mixing the pulverized coal or fly ash with an equal amount of pure Ag powder (99.9998 Ag). The homogenized mixture was then pressed in polyethylene slugs in an isostatic electrode die at $25,000 \mathrm{psi}$ for $1 \mathrm{~min}$. The nominal electrode size was $1 \mathrm{~cm} \times 0.15$ $\mathrm{cm}$. Sets of graded exposures were made from these electrodes so that the concentration range from $0.03 \mathrm{ppm}$ up to the percent range was covefed. Photoplates were interpreted according to the techniques given by Kennicott. (I) In fly ash and coal samples, Fe was determined chemically so the isotopes of Fe gquld be used as an internal standard. Computerized sensitivity values were used.

\section{Isotope Dilution By Spark Source Mass Spectrometry}

A unique and quite different approach to the determination of trace elements in solids, liquids and gases involves the use of the isotope dilution technique. This method has been operational for some time with mass spectrometers, using thermal ionization sources for solids and electron bombardment sources for gases, giving accurate results with small samples; however, not until recently has it bę̧ used for analyzing environmental samples with spark source mass spectrometefsy The general method of isotope dilution has been described by Hintenberger. ${ }^{4}$ For each element to be determined, an enriched isotope, usually of minor abundance, is mixed with the sample. The isotopic ratios, altered by spike additions, are then measured on a portion of the sample by mass spectrometry. Even though the method is limited to elements having two or more naturally occurring or long-lived isotopes, it possesses the great advantaige over other analytical techniques of being very sensitive and accurate, and relatively free from interference effects. Thermal source and electron bombardment mass spectrometers are well suited for isotope dilution, but they display very different sensitivities for various elements; whereas spark source mass spectrometers have similar sensitivities for all elements and can therefore be used without deleterious effects from a complete matrix change.

Fig. 2 shows a mass spectrum of 8 admium spiked with enriched ${ }^{105} \mathrm{Cd}$. The solid line at position 106 represents the ${ }^{106} \mathrm{Cd}$ spike and the dashed lines represent the relative abundances for the other $\mathrm{Cd}$ ifotopes. The dashed line at juxtaposition at 106 is the relative abundances of ${ }^{106} \mathrm{Cd}$ as it occurs in nature. Table I shows the IBM 1130 computer programmed output for a typical isotope dilution analysis. The program is flexible in that the spike size, sample size, spike composition, and percent transmittance can all be variables. The three sets of data under 106 and 114 are percent transmittance for three photoplate exposures taken, and the results are reported in nanograms per gram.

\section{Isotope Dilution BY Thermal Emission Mass Spectrometry}

For the quantitative measurement of $\mathrm{Pb}$ and $\mathrm{U}$ in coal and fly ash and $\mathrm{Pb}$ in gasoline, a three-stage thermal emission mass spectrometer (TEMS) was used (Fig. 3). The hasic design of the instrument is based on that developed by white and collins $1954{ }^{(5)}$ and modified at ORNL. The addition of an electrostatic third stage increased the abundance sensitivity to $10^{8}$ as described by Smith et al.

The two magnetic stages are $30-\mathrm{cm}$ radius followed by an electrostatic analyzer with a radius of $43.25 \mathrm{~cm}$. The vacuum system is of all-metal construction 
and is bakeable to $300^{\circ} \mathrm{C}$. The analyzer region of the instrument is pumped with ion pumps and is maintained at a pressure of $10^{-5}$ torr. A combination titanium sublimatiog-ion pump is used to obtain operating pfessures in the source region in the $10^{-8}$ torr range. A (8) Nier thick-lens source, (7) used in conjunction with a sample wheel arrangement, ${ }^{8}$ makes it possible to analyze as many as ten samples pex: day.

Ions are detected by a secondary electron multiplier behind the receiver slit. The pulses from the multiplier are accumulated in a 400-channel analyzer used in the time base mode. This arrangement allows the maximum sensitivity with respect to sample size. Mass measurements are made by sweeping the accelerating voltage across the region of interest, 233 through 238 for $U_{;} 204$ through 208 for $\mathrm{Pb}$. The determinations of uranium and lead in coal and fly ash and $\mathrm{Pb}$ in gasoline, both quantithativel $\mathrm{y}_{20}$ and isotopically, are done by isotope dilution with enriched spikes of $\mathrm{U}$ and ${ }^{204} \mathrm{~Pb}$.

$\mathrm{Pb}$ Analysis by TEMS. Lead analyses are made utilizing the gel technique described by Cameron et al. 1969. Lead ions are thermally produced at rhenium filament temperatures ranging between $1100-1300^{\circ} \mathrm{C}$ depending somewhat on the sample size. A loading of 10 nanograms provides enough sample to allow an analysis consisting of 10 runs of 200 sweeps across the masses of interest.

U Analysis by TEMS. Uranium ions are thermally produced at rhenium filameit temperatures ranging from $1700-1850^{\circ} \mathrm{C}$. Small quantities (10-100 nanograms) of uranium in the form of $\mathrm{UO}_{2}$ ( $\mathrm{NO}_{3}$ ), produce sufficient ions for a precise analysis. A benzene reduction procedure hals been developed at ORNL which produces only mata? ion signals. This procedure produces a very clean uranium spectrum and increases the sensitivity of the measurement. As in the analysis of lead, an analysis consists of at least 200 sweeps across the masses of interest.

Preparation of Coal and Fly Ash for Isotope Dilution alysis. 2 Sẹparate aliquots of coal and fly ash are weighed out and spiked with $\mathrm{Pb}$ and $233 \mathrm{U}$, respectively. The chemical treatment and extraction of $\mathrm{Pb}$ and $\mathrm{U}$ from coal and fly ash are identical except coal is ashed at $450^{\circ} \mathrm{C}$ before chemical treatment. The samples are dissolved with a mixture of $\mathrm{HF} \cdot \mathrm{HNO}_{3} \cdot \mathrm{HClO}_{4}$ in Teflon beakers. The lead is separated by dithizone extraction, evaporăted to dryness, redissolved in dilute $\mathrm{HNO}_{3}$ and $10 \mathrm{ng}$ loaded on filaments with silica gel for mass analysis.

The uranium is separated after dissolving the sample as described for lead by extraction with TBP from $4 \mathrm{M} \mathrm{HNO}_{3}$. After the organic phase is scrubbed with $4 \underline{M}$ HNO $_{3}$, the uranium is back extracted into distilled water and evaporated to dryness. The uranium is loaded on a rhenium filament by dissolving the purified sample in a small volume of $0.05 \mathrm{M} \mathrm{HNO}_{3}$ for analysis.

Preparation of Gasoline for Isot pe Dilution Analysis. Aliquots of gasoline are spiked with $\mathrm{Pb}$ and treated by either a weffophemical method or the bromine oxidation method described by Griffing and Rozek.

The wet chemical procedure consisted of refluxing first with HNO until the initial reaction subsided, then $\mathrm{HClO}_{4}$ was added to the flask and the reflux continued until the reaction was complete. The resulting solution containing the inorganic lead was finally evaporated to near dryness, diluted to a suitable $\mathrm{Pb}$ concentration with dilute $\mathrm{HNO}_{3}$ and loaded onto Re filaments for M.S. 
In the bromine method, $\mathrm{Br}_{2}$ in $\mathrm{CCl}_{4}$ was added to the gasolines in a test tube. complete conversion to lead bromide was assured by heating. The resulting lead bromide precipitate was dissolved with dilute $\sim_{1} \mathrm{M}$ HNO ${ }_{3}$. The mixture was centrifuged and the organic layer discarded; the aqueous solution was adjusted for M.S. analyses. Either of the procedures works satisfactorily, but the $B r_{2}$ method is much easier, faster and has less possibility for contamination.

\section{RESULTS AND DISCUSSION}

The bulk of the samples for this study came from TVA's Allen Steam Plant at Memphis, Tennessee. The sampling points (Fig. 4) included inlet air, coal, bottom ash, precipitator inlet and outlet at the 268 -ft. stack level. During the two-yeek sampling period the unit was operated under steady state conditions at 240 MT with a uniform coal supply so that a mass balance might be established for a number of elements. All the coal from southern Illinois was washed and crushed by TVA so that 908 was $<4$ mesh. Nominal coal analysis indicated the following composition: 9.58 moisture, 348 volatiles, 438 fixed carbon, 138 ash and 3.48 sulfur.

The isotope dilution results in Table II are on fuel source samples considered homogeneous; these samples were obtained from NBS. The results in Table III are from the sampling points as indicated in Fig. 4. These summarized results are mostly by the SSMS general scan technique; the general scan technique has an estimated accuracy of better than \pm 50 percent, while the iscitope dilution measurements are limited by the emulsion detector to $\pm 3-5 \%$. The results are in terms of grams of metal flow per minute. The mass balance fior the various elements was computed by the following equations:

$$
\begin{gathered}
Q_{c}(m)=c_{c}(m) \times(g \mathrm{coal} / \mathrm{min}) \\
Q_{P i}(m)=c_{P i}(m) \times(g \mathrm{fly} \mathrm{ash} / \mathrm{min}) \\
Q_{b a}(m)=c_{b a}(m) \times(g \text { ash in coal }-g f l y \mathrm{ash} / \mathrm{min}) \\
\text { Imbalance, } \&=\frac{\left(Q_{P i}+Q_{b a}-Q_{c}\right) 100}{Q_{c}}
\end{gathered}
$$

where $Q_{c}^{(m)}, Q_{P i}^{(m)}+Q_{b a}^{(m)}$ are flow rates of metal $(m)$ in $g m^{-1}$ for coal, precipitator inlet and bottom ash, respectively, and $c(m)$ is concentration in weight fraction. Coal consumption during the sampling was at a rate of 82.5 tons $\mathrm{hr}^{-1}$, or
$1.25 \times 10^{-6} \mathrm{~g} \mathrm{~min}^{-1}$, and the fly ash flow rate was measured at $4.9 \times 10^{4} \mathrm{~g} \mathrm{~min}^{-1}$.

The metal balance for all the elements analyzed by mass spectrometry is good, but on the average shows a negacive imbalance of 208. Metals showing high imbalance, i.e.. Hg, As and Se probably were in the gaseous state at the sample points. An example of this was ${ }_{1}$ the case for $\mathrm{Hg}$ in which a precipitator outlet sample showed a flow of $0.02 \mathrm{~g} \mathrm{~min}^{-1}$, and at a point of this sampling the particulates are much cooler than the fly ash at the precipitator inlet. 
The average imbalance for the elements measured by isotope dilution mass spectrometry with lower volatility showed an imbalance range from -88 to +128 ; these results indicate the usefulness of mass spectrometry in evaluating environmental impacts.

\section{ACKNOWLEDGMENTS}

The authors gratefully acknowledge the assistance and cooperation of the many personnel of the Tennessee Valley Authority. This work was supported by the National Science Foundation Interagency Agreement No. AEC 40-237-70 and NSF AG 398. The work was carried out at ORNL which is operated by union Carbide Corporation for the U. S. Atomic Energy Commission. 


\section{REEERENCES}

1. P. R. Kennicott, "Interpretation of Mass Spectrograph Plates," in Trace Analysis by Mass Spectrometry, (A. J. Ahearn, ed.), pp. 136-210. Academic Press, N. Y. (1972).

2. J. A. Carter and J. R. Sites, unpublished relative sensitivity values, 1972.

3. J. A. Carter et al., "Environmental spectrometry," Ann. Chem. Div. Ann. Progr. Rep. Sept. 30, 1972, ORNL-4838, Pp. 44-46.

4. H. Hintenberger, "A Survey of the Use of Stable Isotopes in Dilution Analyses," in Electromagnetically Enriched Isotopes and Mass Spectrometry,

5. F. A. White and T. L. Collins, Appl. Specty. 8, 169 (1954).

6. David H. Smith et al., Int. J. Mass Spectrom. Ion Phys., 10, 343 (1972/1973).

7. A. O. Nier, Rev. Sci. Instr. 18, 398 (1947).

8. W. H. Christie and A. E. Cameron, Rev. Sci. Instr. 37, 336 (1966).

9. A. E. Cameron, D. H. Smith and R. L. Walker, Anal. Chem. 41, 525 (1969).

10. M. E. Griffing et al., Anal. Chem. vol. 29, 190, Feb. 1957.

11. N. E. Bolton et ai.., Trace E'lement Measurements at the Coal-Fired AlZen Stean Plant Progress Report, March 1973, ORNL-NSF-EP-43. 
$=\quad \because \quad$ Table I

Sample Computer Output for Cadmium by Isotope Dilution Spark-Source Mass Spectrometry

\begin{tabular}{|c|c|c|c|c|c|c|}
\hline$C D$ & & 06 & 124 & VOL & \multicolumn{2}{|c|}{ CONCK } \\
\hline \multirow[t]{2}{*}{$\begin{array}{l}\text { SPIKE } \\
\text { SAMPLE }\end{array}$} & & $\begin{array}{l}400 \\
220\end{array}$ & $\begin{array}{r}2.500 \\
28.900\end{array}$ & $\begin{array}{l}1.000 \\
1.000\end{array}$ & 1.0 & \\
\hline & SA & PLE & & & 106 & 114 \\
\hline $\begin{array}{r}5 \\
5 \\
5\end{array}$ & $\begin{array}{l}\text { SOIL } \\
\text { SOIL } \\
\text { SOIL }\end{array}$ & $\begin{array}{l}318 F \\
318 \\
318 F\end{array}$ & $\begin{array}{l}40 \\
40 \\
39\end{array}$ & & $\begin{array}{l}19.3 \\
46.9 \\
64.6\end{array}$ & $\begin{array}{l}16.2 \\
41.3 \\
60.0\end{array}$ \\
\hline
\end{tabular}


Table II

ISOTOPE DILUTION RESULTS

Sample Type

\begin{tabular}{cccc}
\multicolumn{4}{c}{ Concentration, wt } \\
\hline $\mathrm{U}$ & Pb & Pb & Cd \\
TEMS & TEMS & SSMS & SSMS \\
\hline & & 28 & 0.28 \\
1.22 & & 26 & 0.34 \\
1.18 & & 28 & 0.32 \\
1.22 & & 30 & 0.32 \\
1.22 & & &
\end{tabular}

Fly Ash

11.9

11.7

11.6

11.6

$\begin{array}{ll}79 & 1.8 \\ 78 & 2.2 \\ 79 & 1.9 \\ 76 & 1.5\end{array}$

Gasoline $^{(a)}$

$285^{(b)}$

282

284

283

$284^{\text {(c) }}$

284

285

279

Fuel oil (a)

$\begin{array}{ll}0.27 & 0.022 \\ 0.28 & 0.021 \\ 0.26 & 0.018 \\ 0.23 & -\end{array}$

(a) Results in $\mu \mathrm{g} / \mathrm{ml}$;

(b) Wet cxidation;

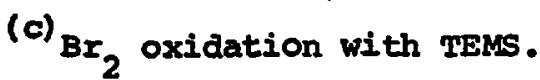


Table III

IMPURITY MASS FLOW IN A STEAM PLANT (Flow rate in $\mathrm{g} \mathrm{min}^{-1}$ )

\begin{tabular}{|c|c|c|c|c|}
\hline Element & Coal & $\begin{array}{c}\text { Bottom } \\
\text { Ash }\end{array}$ & $\begin{array}{c}\text { Precipitator } \\
\text { Inlet }\end{array}$ & $\begin{array}{c}\text { Imbalance } \\
8\end{array}$ \\
\hline Al & 13,000 & 5,500 & 7,300 & -1.5 \\
\hline $\mathrm{Ca}$ & 6,000 & 3,300 & 1,500 & -20 \\
\hline Fe & 25,000 & 10,000 & 4,900 & -40 \\
\hline $\mathbf{K}$ & 700 & 550 & 340 & +27 \\
\hline$M g$ & 1,800 & 770 & 340 & -38 \\
\hline $\mathbf{N a}$ & 370 & 220 & 150 & 0.0 \\
\hline $\mathbf{T I}$ & 880 & 220 & 240 & -48 \\
\hline Mn & 130 & 110 & 34 & +11 \\
\hline$A_{3}$ & 6.2 & 0.22 & 2 & -64 \\
\hline $\mathrm{Be}$ & $<5$ & $<1.1$ & 0.83 & -- \\
\hline$c a^{a}$ & 0.63 & 0.30 & 0.28 & -7.9 \\
\hline $\mathrm{Cu}$ & 63 & 22 & 19 & -35 \\
\hline $\mathrm{Pb}^{\mathrm{a}}$ & 9.3 & 0.45 & 10 & +12 \\
\hline$N i$ & $<100$ & 55 & 24 & -21 \\
\hline $\mathbf{S b}$ & & 0.8 & 0.5 & -- \\
\hline $\mathrm{Se}$ & 7.5 & 2.2 & 1 & -58 \\
\hline $\mathbf{v}$ & 37 & 11 & 17 & -24 \\
\hline $\mathrm{zn}^{\mathrm{a}}$ & 110 & 2.0 & & -7.3 \\
\hline $\mathrm{Hg}^{2}$ & $.08^{b}$ & $.007^{b}$ & .007 & * \\
\hline
\end{tabular}

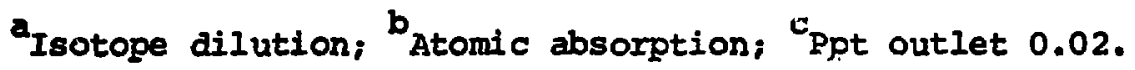
*uost Hg flow is in stack gas. 


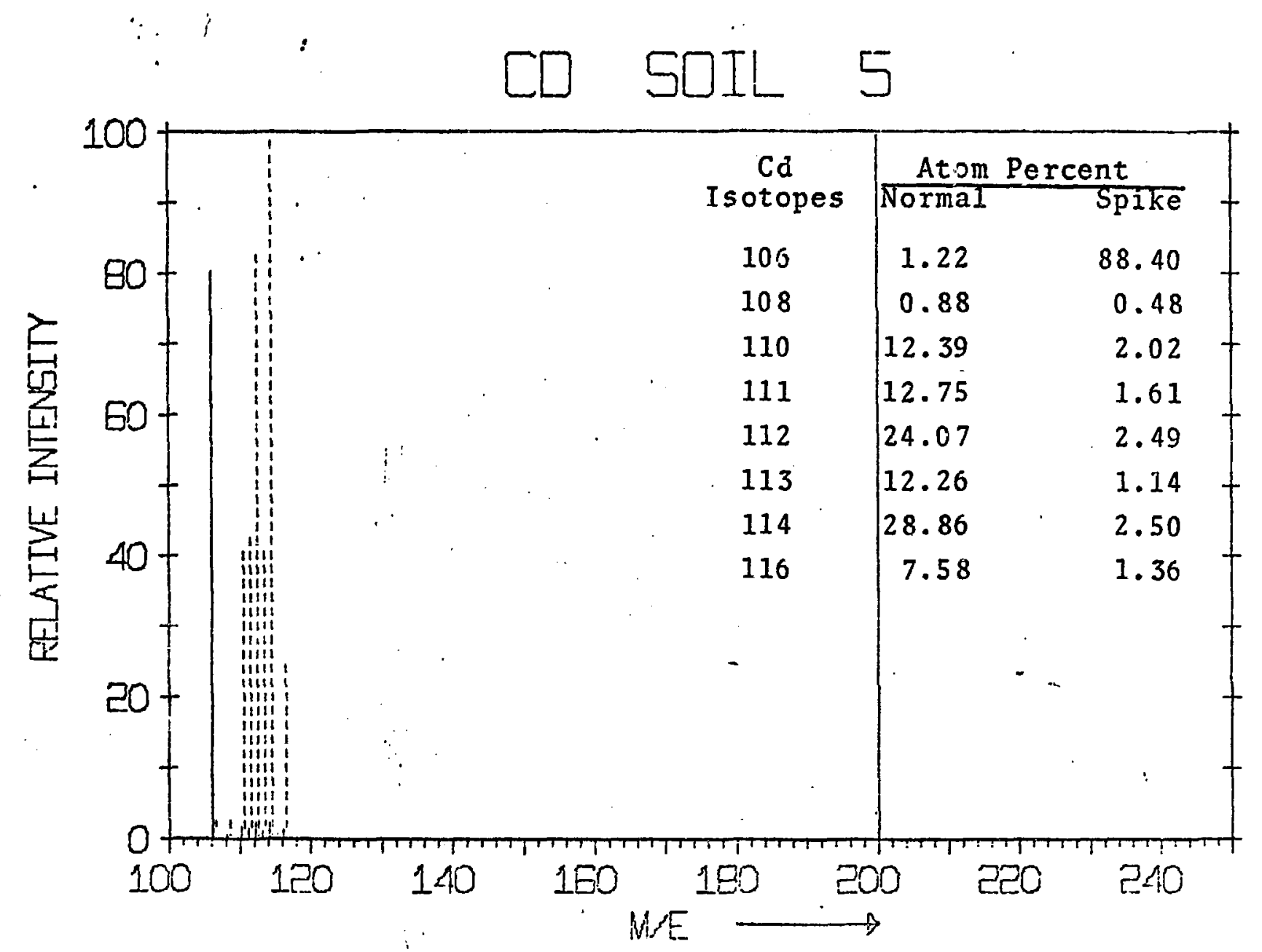

Fig. 2. Cadmium Spectrum - Spiked With Enriched ${ }^{106} \mathrm{Cd}$ 


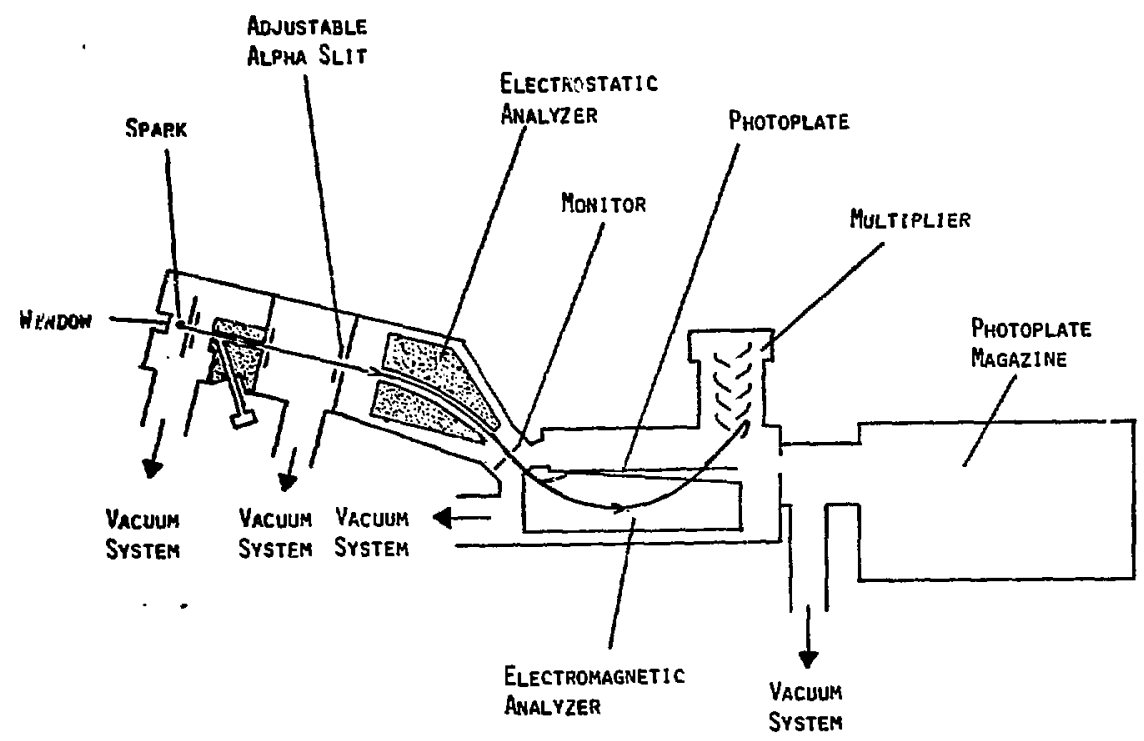




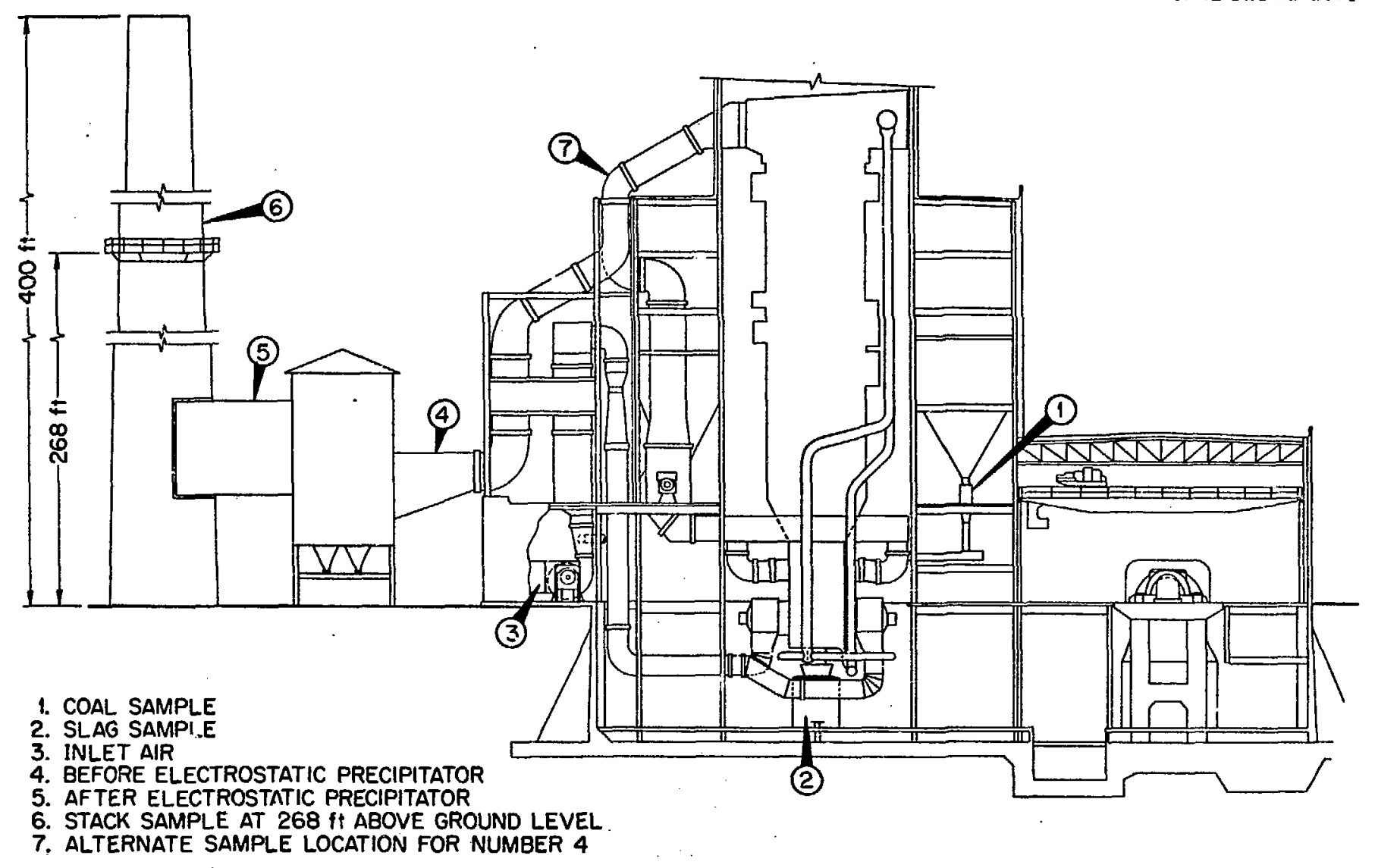

Fig. 2. Schematic of Number 2 Unit, Allen Steam Plant, Memphis. 
ORNL-OWG. 70-9157

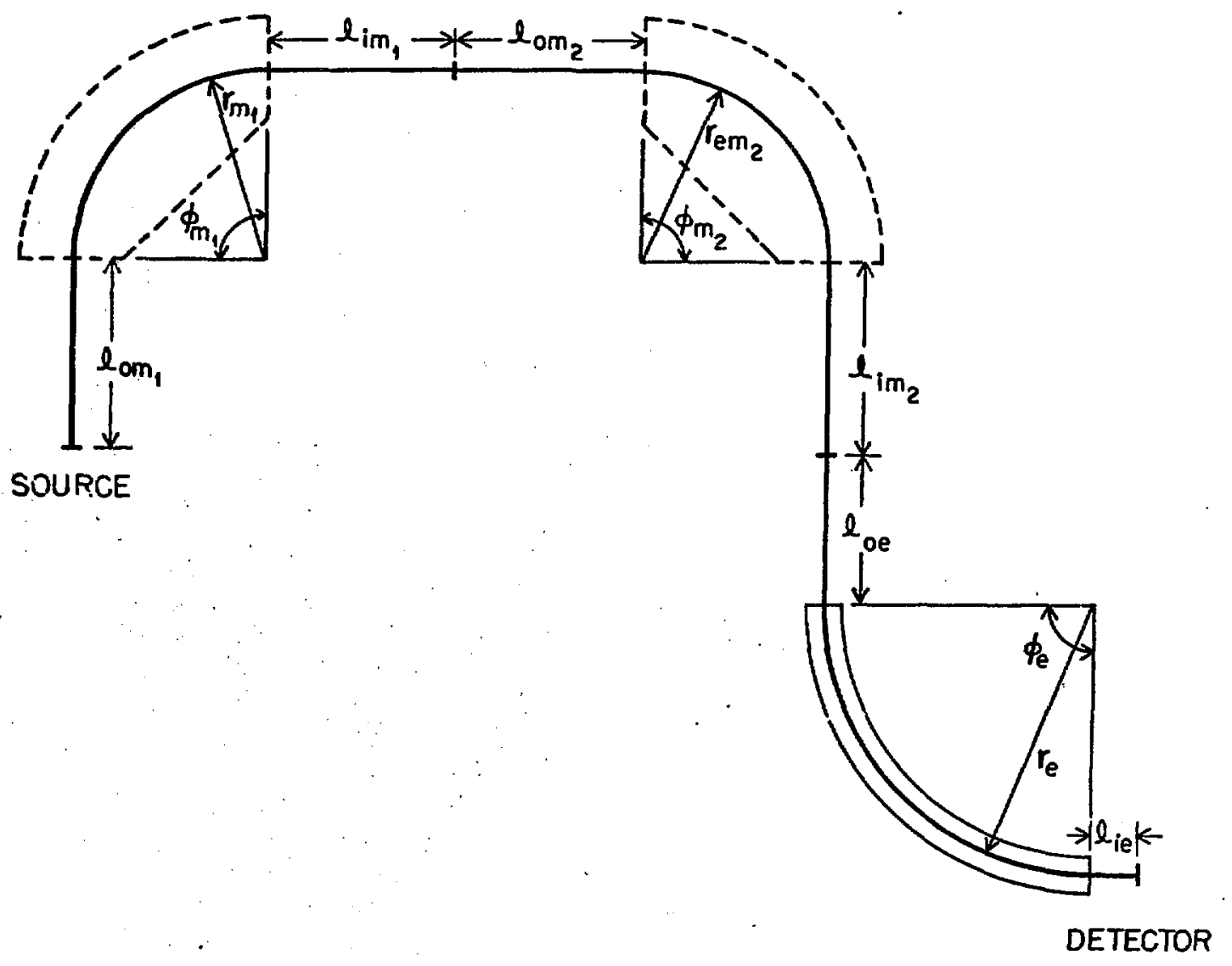

Schematic diagram of the three-stage mass spectrometer. 